\title{
Caring for a febrile child: \\ The quality of Internet information
}

\author{
Gaby Haddow, Curtin University of Technology, School of Nursing \& Midwifery \\ Robin Watts, WA Centre for Evidence Based Nursing \& Midwifery of the J oanna Briggs Institute
}

Aim: A small study was conducted to evaluate the quality of information on the Internet about caring for a child with fever in order to alert nurses to the variable nature of information on the Internet for their own professional use and to provide advice to their patients.

Methods: Three search engines were used to locate web sites with information about the management of fever. A total of 22 web sites were assessed after duplicate and irrelevant web sites were excluded from the analysis. Each site was evaluated against the criteria: accuracy; currency; source; original source; and disclosure. The web sites were also examined for warnings against potentially dangerous treatments.

Results: The quality of information on the Internet about the management of fever varied greatly, but was generally poor. Accuracy was assessed using five recommendations for managing fever and the proportion of web sites that included these recommendations ranged from $5 \%$ to $64 \%$. Less than two-thirds of the sites recorded their creation or review dates. A third of the web sites did not carry warnings about potentially dangerous treatments.

Conclusion: This study's findings highlight the poor quality of health information on the Internet and indicate factors to consider when using the Internet as an information source. Nurses' awareness of the variable quality of information on the Internet will assist them to identify quality information for their own professional practice and knowledge on which to base advice to patients.

Key words: health information, Internet, fever management

Dr Gaby Haddow PhD BAppSci(Hons), Research Project Officer, WA Centre for Evidence Based Nursing \& Midwifery of the J oanna Briggs Institute, Curtin University of Technology, School of Nursing \& Midwifery. Email: G.Haddow@ curtin.edu.au

Professor Robin Watts PhD MHSC BA DipNEd RN FRCNA,

Director WA Centre for Evidence Based Nursing \& Midwifery of the J oanna Briggs Institute

\section{Introduction}

Fever is a common childhood complaint that causes considerable concern in parents. With the increasing use of the Internet to locate information of all kinds, it might be expected that many parents are turning to this source for information to help them to care for their feverish child. H owever, there is an extensive body of literature relating to the variable quality of health information on the Internet and how the quality of this information can be most effectively assessed.

\section{Background}

It is important that nursing practitioners have an appreciation of the nature of information on the Internet in their field and that they are able to assess the quality of that information. N urses who turn to the Internet for information with this knowledge will be able to identify relevant and credible information for their own practice and possess the expertise to caution their patients if they are using the Internet as an information source.

This study was carried out to assess the quality of health information on the Internet about the care of febrile children and compare this information with the findings of a recently published systematic review (Watts et al 2001) undertaken by the Western Australian Centre for Evidence Based N ursing and M idwifery. A Best Practice Information Sheet (BPIS) about management of the child with fever (T he Joanna Briggs Institute for Evidence Based Nursing and M idwifery 2001) was published in 2001 as a result of this systematic review.

For the purposes of this study, the BPIS recommendations and findings about the management of children with fever were considered to be the best evidence to be used as a comparison to determine the accuracy of web material (Wyatt 1997). A similar study about fever information on the Internet (Impicciatore et al 1997) provided the basis for this current study and allowed some comparisons to be made between the findings of the two studies.

Impicciatore et al's study (1997) examined 41 World Wide W eb (WW W) sites for information about the treatment of febrile children at home. Information about treating fever was evaluated against a number of measures, including defining a fever, how to take a child's temperature, and advice relating to 
pharmacological and physical treatments. Using these measures the information on each website was compared with guidelines from El-Radhi and Carroll's Fever in paediatric practice (1994). O nly four of the 41 websites examined carried information that 'adhered closely' to the guidelines. The study's findings led the authors to conclude there is an urgent need to check public oriented healthcare information on the Internet for accuracy, completeness, and consistency' (Impicciatore et al 1997 p1878), a conclusion reiterated by Pandolfini and Bonati in a follow up study in 2001 (Pandolfini \& Bonati 2002).

These and other concerns, such as currency of information and lack of accountability, are widely discussed in the literature of health science (Bower 1996, Silberg et al 1997, Van Der Weyden 1997, Wyatt 1997, Eysenbach et al 1998). A recent issue of the BMJ (Purcell et al 2002) on this theme offers further evidence of the growing interest in evaluating health information on the Internet.

\section{It is important for nurses to emphasise to parents that the quality of information on the Internet is highly variable and is not recommended as a replacement for consultation with a health care professional.}

The context in which health information appears on the Internet is also important because this provides users with some idea of the purpose, intended audience, and credibility of the information (Eysenbach et al 1998). Using the term 'context deficit', Eysenbach et al listed a number of ways that Internet users could be misled by information found on web sites. O ne example of 'context deficit' occurs when a search engine takes users directly to a web site without first accessing introductory information, such as a title page, which may carry 'disclaimers and warnings'.

To address concerns about health information on the Internet a number of assessment tools have been developed that set out criteria for judging the quality of this information. These tools range from a simple list of criteria to sophisticated software programs that filter information found on the Internet ( $\mathrm{H}$ ealth Summit Working Group 1997, Pealer \& D orman 1997, Eysenbach et al 1998, H ealth On the N et Foundation 2000, BIO M E Special Advisory Group on Evaluation 2001). Wilson (2002) has classified the tools into five categories: codes of conduct; quality labels; user guides; filters; and third party certification.

\section{Methods}

\section{Search strategy}

As the purpose of this study was to assess the quality of information on the Internet for parents of febrile children, Wyatt's suggestion that sites for evaluation should be those that would be located by typical users' was followed (Wyatt 1997 p1879). Wyatt offers no definition of a typical user and so for the purposes of this study we defined our typical user as an average parent with no medical background and no searching expertise. The search was therefore conducted on three popular search engines using two terms and a simple search string - 'fever AND child'. Two studies (Bidwell 2000, Eysenbach \& Kohler 2002) support this decision with their findings that searchers use an average of 1.7 words in a query (Bidwell 2000) and two-thirds of the 280 searches in Eysenbach and Kohler's study (2002) consisted of oneword only.

In the earlier study by Impicciatore et al (1997), search terms were entered in languages other than English. Resources were not available to translate non-English language web sites in this study, therefore only English terms were used in the search.

The search was conducted in M arch 2002 using three different types of WW W search engine: AltaVista, Google, and Yahoo!. AltaV ista uses search software to locate web sites that include the same terms as those entered in a searcher's query. Google locates web sites based on the search terms and the number of links from other sites to those sites. Yahoo! is a web directory that employs human editors to organise web sites into subject areas.

In this paper we have used the term web page to mean a single page with its own URL, which may or may not link with other pages. The term web site refers to one or more web pages that are collected and linked by the same creator and share the first few elements of the URL. For example, a university web site will have links to hundreds of its own different web pages.

\section{WWW sites located}

The total number of web sites retrieved from the three searches was recorded, but only the first three pages of search results were followed up in the data analysis. The rationale behind this decision was that search engines claim to provide some automated relevance ranking or human editing of web sites that should result in the most useful sites being listed first. Furthermore, previous research has shown that Internet searchers do not explore more than a couple of pages of search results. In a recent study by Eysenbach and Kohler (2002), only nine of 17 participants explored the second page of results (each page listed 10 web sites) and of these only five participants clicked on a link listed on the second page.

The results for the three searches were combined after duplicate sites were excluded and irrelevant sites discarded. Relevance was determined by examining the web site for information about treating fever in children. For example, web sites about different types of fever, such as rheumatic fever, were judged irrelevant. Web sites that merely listed links to other sites and those for which a clear link to the information was not evident were also discarded.

AltaVista and Google search engines list 10 search results on each page, that is 30 links in the first three pages of results. Some of these links originated from the same web site, and many of the pages were not relevant to this study. The AltaV ista search found a total of 159,322 results and the Google search listed 493,000 links. Yahoo! retrieved only eight results, all of which were irrele- 
vant to the topic. After excluding the irrelevant sites on AltaV ista, 10 useful web sites remained. The same procedure was carried out for the sites found in the Google search, resulting in 21 relevant web sites. There was some duplication between the sites found in AltaV ista and Google searches and when these were excluded there were 22 individual web sites left for analysis.

\section{Data extraction}

Each web site located in the searches was assessed using criteria from the $\mathrm{H}$ ealth Summit Working Party document $(\mathrm{H}$ ealth Summit Working Group 1997). This tool, in Wilson's (2002) 'code of conduct' category, lists criteria for evaluating health information on the Internet: credibility; content; disclosure; links; design; interactivity; and caveats. Within each of these criteria are sub-criteria from which 10 assessment priority issues were identified. The first five of these (source, disclosure, accuracy, currency, and original source stated) contributed to evaluating the information on the Internet about fever management of children in this study. As well as being developed by a reputable source, the five assessment criteria have an additional benefit in that they involve relatively objective judgements. $O$ bjectivity has been noted as an important aspect when selecting criteria with which to assess the quality of information on the Internet (Jadad \& G agliardi 1998).

An additional criterion was included as a response to the earlier study's findings that some web sites were recommending aspirin use and cold sponging/baths (with or without alcohol) (Impicciatore et al 1997). These treatments are no longer considered safe for the treatment of fever in children and therefore the current study assessed the web sites for warnings about their potential dangers.

The five evaluation criteria of the $\mathrm{H}$ ealth Summit Working Party are:

- accuracy - checked against a credible source, in this case the Best Practice Information Sheet;

- currency - when created and last reviewed;

- source - web site creators' name(s), qualifications, conflict of interest, bias;

- original source stated - reference to sources, affiliation and credentials of authors; and

- disclosure - mission statements, purpose, use of information entered by user.
To address the concern that health information could be dangerous to consumers without adequate context information, a further criterion was explored:

- warnings that alerted readers to the dangers of treating fever with aspirin and cold water (with or without alcohol) sponging/baths.

In accordance with Wyatt's (1997) recommendations the accuracy of health information on the Internet was assessed using the best evidence, provided in this research by the fever BPIS. The data in the web sites were evaluated for accuracy in terms of recommendations about:

- sponging;

- use of paracetamol;

- fluid intake; and

- type of clothing and/or wrapping a febrile child.

These recommendations stated that 'routine use of sponging to reduce fever is not supported', that paracetamol should be used with caution and 'routine sustained administration of paracetamol to treat mild or moderate fever is not supported' (T he Joanna Briggs Institute for Evidence Based N ursing and M idwifery 2001). The BPIS also recommended 'interventions that assist the body's physiological responses to infection' such as encouraging fluids and light clothing and/or not covering a feverish child.

\section{Results}

\section{Accuracy}

Table 1 shows the number of web sites that agreed with, disagreed with, or did not mention the five recommendations of the BPIS.

$O$ verall the accuracy of the web sites was poor when compared with the recommendations of the BPIS. Sponging was recommended as a treatment in over half the web sites (12, $55 \%)$, with less than a quarter of the sites $(5,23 \%)$ providing information that agreed with the recommendations of the BPIS. Advice about being cautious in the administration of paracetamol was given by seven web sites (32\%), but more concerning is that only one web site suggested a single dose of paracetamol might be adequate when caring for a child with fever. $\mathrm{O} n$ the other hand, 13 web sites (nearly 60\%) advised giving paracetamol up to four hourly to treat a fever. There were eight web sites $(36 \%)$ that provide no advice at all about how often paracetamol should be administered to a feverish child.

Table 1: Accuracy of information in the web sites

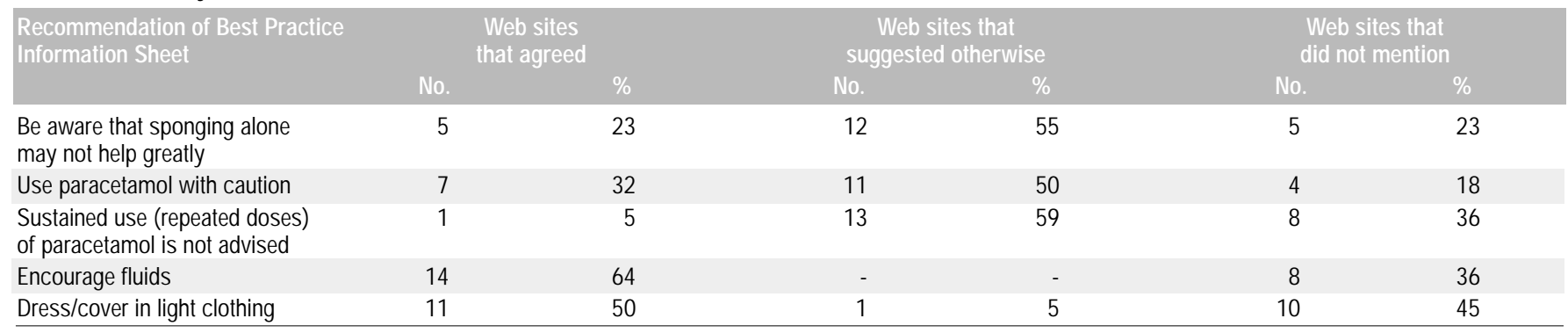

Percentages may not add to 100 due to rounding 
A better result was found when the web sites were examined for advice about encouraging fluids when caring for a child with fever. Fourteen (64\%) web sites provided this information. However, the accompanying recommendation in the BPIS, to use light clothing or coverings, was advised by only 11 (50\%) of the web sites.

\section{Currency}

When the web sites were examined for currency in this study, over half $(13,59 \%)$ recorded a creation date between 1996 and February 2002. M ost of these sites were relatively current with eight (36\%) created in the last two years, from 2000 onwards. H owever, nine web sites (41\%) did not record a creation date at all. A further aspect of currency, that is when the information on the web site was last reviewed or updated, was also explored. $\mathrm{H}$ alf the web sites (11) did not list information about update or review dates. Seven of the sites $(32 \%)$ did note review dates. The remaining four sites ( $18 \%$ ) had static dates, such as dates of a monograph publication or journal issue.

\section{Source}

One web site was classed as anonymous, listing no information to indicate who was responsible for compiling the information. The remaining 21 (95\%) web sites recorded the name of the producer or creator and two-thirds of these (14 web sites, 64\%) also noted their qualifications and/or credentials.

The majority, 13 of the 22 web sites (59\%), were commercial ventures. Individuals, health services, academic institutions and organisations were responsible for creating just over a third of the sites $(8,36 \%)$. O verwhelmingly the sites had their origins in the U nited States. N ineteen of the 22 web sites (86\%) were from the United States, with one site each originating from the United Kingdom, Canada and M alaysia.

\section{Original source}

There are two aspects to the criterion 'original source': a reference to a name, organisation, book, article or other information source recorded as the original source of the information on the web site; and details about the affiliation of the original source. For example, does the author work in an academic institution, hospital, commercial organisation, etc. Thirteen (59\%) web sites recorded information about an original source, but only eight of these sites listed their affiliations.

\section{Disclosure}

Disclosure relates to producers of web sites outlining the purpose or objectives of the site. It also refers to profiling, which is when users of a site are asked to enter personal information. If this occurs the users should be informed about possible later use of this information. O nly half of the web sites (11) in the sample declared their purpose and/or objectives. $\mathrm{N}$ one of the web sites featured a feedback box, although some offered email addresses for users to ask 'an expert' specific questions.

\section{Warnings}

Information relating to warnings about treatments that might be harmful is equally important to the health consumer as accurate information about useful treatments. In particular, warnings serve to alert people to treatments that might have been common practice in the past but have been found to be potentially dangerous in subsequent research. Cold water sponging or baths (with or without alcohol) and aspirin use are all treatments that fall into this category. Table 2 lists the findings for the web sites when examined for these warnings.

\section{Table 2: Warnings given by web sites}

\begin{tabular}{|c|c|c|c|c|}
\hline \multirow[t]{2}{*}{ Warning } & \multicolumn{2}{|c|}{$\begin{array}{c}\text { Web sites that gave } \\
\text { warning }\end{array}$} & \multicolumn{2}{|c|}{$\begin{array}{l}\text { Web sites that dic } \\
\text { not give warning }\end{array}$} \\
\hline & No. & $\%$ & No. & $\%$ \\
\hline Cold baths/sponging & 12 & 55 & 10 & 45 \\
\hline Aspirin use & 15 & 68 & 7 & 32 \\
\hline $\begin{array}{l}\text { Alcohol added to water } \\
\text { for bathing or sponging }\end{array}$ & 12 & 55 & 10 & 45 \\
\hline
\end{tabular}

Warnings about cold baths or sponging (with or without alcohol) were noted by 12 (55\%) web sites. Aspirin use warnings were carried by a larger number of web sites $(15,68 \%)$.

\section{Discussion}

In Table 3 our findings for the number of web sites assessed against the five priority criteria developed by the $\mathrm{H}$ ealth Summit Working Party (H ealth Summit Working Group 1997) are presented. A range is given for those criteria with more than one factor involved in the assessment. For example, accuracy was assessed using five recommendations from the BPIS.

The results were also examined to identify how many of the web sites provided quality information across all the criteria. O nly three of the 22 web sites carried information that met the accuracy, currency, source, original source, disclosure, and warnings criteria. That is, these three web sites provided quality information for at least three of the five aspects of accuracy, were relatively current, included source, original source and disclosure information, and carried warnings about potentially dangerous treatments.

The criterion of 'source' included identifying the names, background information and qualifications of the producers of the web site. Bias and conflict of interest are also aspects of source, but were not pursued in this study when it became clear that it would be very difficult to assess whether bias and/or conflict of interest were evident in the web sites.

W hile the web sites performed well in terms of source information, their assessment against the other four criteria showed a substantial drop in the number that met the criteria. Particularly concerning are the results for accuracy of information. If the findings for one of the recommendations, that children with 
Table 3: Information on the web sites using

Health Summit Working Party criteria

\begin{tabular}{lc} 
Criteria & Web sites that met criteria \\
& $\%$ \\
Accuracy & $5-64$ \\
Currency & 59 \\
Source & $64-95$ \\
Original source stated & $36-59$ \\
Disclosure & 50 \\
\hline
\end{tabular}

Range given if more than one factor was assessed within a criterion

fever are encouraged to take more fluids, are excluded, $50 \%$ of the web sites, at best, agree with the recommendations of the BPIS. It is clear from these results that users of health information on the Internet could be badly misled. It is important for nurses to emphasise to parents that the quality of information on the Internet is highly variable and is not recommended as a replacement for consultation with a health care professional.

The relevance and accuracy of information of all kinds, but particularly health information, change as new knowledge in the field is gained. Information provided should reflect current knowledge and practice. For this reason the systematic reviews conducted under the umbrella of the Cochrane Collaboration (Clarke \& Oxman 2001) are expected to be updated every few years with reviewers recording the most recent update date. It was discouraging to find that almost half of the web sites examined did not record their creation date and only a third of the sites had information that indicated the site had been updated.

\section{Of the 22 sites examined in this research only three provided quality advice across all criteria examined.}

The study also examined whether the sites found carried the type of information content that was suitable to average parents, our 'typical users'. For example, did the search retrieve sites that demanded a high level of medical knowledge and terminology of the readers? We found that most of the web sites were written in an easily readable style, although two sites were clearly written for readers with extensive medical knowledge.

As a reflection of how many of these web sites self-regulated in terms of evaluating themselves against assessment tools available, only two of the sites declared this information, both displaying the $\mathrm{HON}$ ( $\mathrm{H}$ ealth on the $\mathrm{Net}$ ) logo ( $\mathrm{H}$ ealth on the $\mathrm{N}$ et Foundation 2000). According to Wilson (2002), the H O N code of conduct is a quality label used by over 3000 websites.

D espite the concerns expressed above, there are some encouraging indicators that information on the Internet, at least as regards potentially dangerous treatments, has improved in the intervening five years between the study by Impicciatore et al (1997) and our study. The results of the current study show that more web sites carried the warnings than did not, but a sizeable proportion of the sample of sites could be improved in this respect. When the earlier study examined treatment information on web sites, between $22 \%$ and $29 \%$ of the sites discouraged cold sponging or baths, whereas our study found over $50 \%$ of web sites carried this warning. A higher number $(51 \%)$ of sites in the earlier study discouraged using alcohol in water for baths or sponging, which is similar to our finding of $55 \%$, but two of the Impicciatore et al sites (5\%) advocated the use of aspirin. In common with our findings, the follow up study by Pandolfini and Bonati (2002) found no web sites that suggested using aspirin.

\section{Limitations of the study}

The methods used to select a collection of web sites to analyse were implemented in order to reproduce the kind of search result that a 'typical user' (Wyatt 1997) might achieve. While we have defined our typical user as an average parent who does not have a medical background or searching expertise, there is no way of ascertaining the search results they would retrieve without carrying out a separate study of their searches for the same topic. H owever, the way in which the search was conducted was based on previous studies that had examined how consumers had searched for information on the Internet (Bidwell 2000, Eysenbach \& Kohler 2002). Although the results cannot claim to reflect precisely the Internet information a different search might find, given the enormous amount of information on the Internet, the web sites examined in this study are potentially as random as the results of any search using other combinations of the terms.

\section{Conclusion}

An extensive body of literature exists expressing concerns about the quality of health information on the Internet and many efforts have been made to create quality assessment tools to evaluate this information. A study such as this one serves to reinforce the point that users of health information on the Internet should be cautious. Of the 22 sites examined in this research only three provided quality advice across all criteria examined. At best, web sites lacked sufficient information to judge the quality, and at worst, the inadequacy of the information given was potentially dangerous.

The results of this study provide a valuable reminder that information on the Internet is not always accurate, current or complete. It is important that nurses and patients are aware of these deficiencies of some Internet information.

In conclusion, we would recommend that nurses should be introduced to the issues surrounding the quality of information on the Internet in the education programs they complete to qualify as nurses and in any ongoing professional development programs. This education should include criteria with which to assess information on the Internet and outline the deficiencies 
of some of this information. We also recommend that nurses provided with this knowledge implement it in practice when assisting patients and thereby facilitate their empowerment as health consumers.

\section{Acknowledgements}

The authors wish to thank Jeanette Robertson for her advice in the initial stages of this study about searching strategies on the Internet. Jeanette's comments on the paper's structure and content are also greatly appreciated.

\section{References}

Bidwell P 2000 In search of quality: the tools and techniques of health researchers on the Internet. LASIE: Information Bulletin of the Library Automation Systems Information Exchange 31(3):30-41

BIOME Special Advisory Group on Evaluation 2001 How to evaluate an Internetbased information source [Online]. Retrieved February 8, 2002 from the World Wide Web: http://biome.ac.uk/guidelines/eval/howto.html

Bower H 1996 Internet sees growth of unverified health claims. British Medical J ournal 313(7054):381

Clarke M, Oxman A D (eds) 2001 Cochrane reviewers handbook 4.1.4 [updated October 2001]. In: The Cochrane Library, Issue 4, 2001, Update Software Oxford

El-Radhi S, Carroll J 1994 Fever in paediatric practice. Blackwell, Oxford

Eysenbach G, Diepgen T L, Muir Gray J A, Bonati M, Impicciatore P, Pandolfini C, Arunachalam S 1998 Towards quality management of medical information on the internet: evaluation, labelling, and filtering of information. British Medical J ournal 317(7171):1496-1502

Eysenbach G, Kohler C 2002 How do consumers search for and appraise health information on the world wide web? Qualitative study using focus groups, usability tests, and in-depth interviews. British Medical J ournal 324(9 March):573-577
Health on the Net Foundation 2000 HON's initiatives and services: MARVIN [Online]. Retrieved February 8, 2002)from the World Wide Web: http://www.hon.ch/Project/Marvin project.html

Health Summit Working Group 1997 Criteria for assessing the quality of health information on the Internet: Mitretek Systems and AHCPR [Online]. Retreived February 21,2002 ) from the World Wide Web: http://www.ahrq.gov/data/infoqual.html

Impicciatore P, Pandolfini C, Casella N, Bonati M 1997 Reliability of health information for the public on the world wide web: systematic survey of advice on managing fever in children at home. British Medical J ournal 314(7098):18751881

J adad A, Gagliardi A 1998 Rating health information on the Internet: navigating to knowledge or to Babel? J AMA: J ournal of the American Medical Association 279(8):611-614

Pandolfini C, Bonati M 2002 Follow up of quality of public oriented health information on the world wide web: systematic re-evaluation. British Medical J ournal 324(9 March):582-583

Pealer L N, Dorman S M 1997 Evaluating health-related Web sites. J ournal of School Health 67(6):232-235

Purcell G P, Wilson P, Delamothe T 2002 The quality of health information on the internet. British Medical J ournal 324(9 March):557-558

Silberg W M, Lundberg G D, Musacchio R A 1997 Assessing, controlling and assuring the quality of medical information on the Internet: caveat lector et viewor - let the reader and viewer beware. J AMA: J ournal of the American Medical Association 277(15):1244-1246

The J oanna Briggs Institute for Evidence Based Nursing and Midwifery 2001 Management of the child with fever. Best Practice 5(5):1-6

Van Der Weyden M B 1997 Medical information and the World Wide Web. Medical J ournal of Australia 167:571-572

Watts R, Robertson I, Thomas G 2001 The nursing management of fever in children: a systematic review. The J oanna Briggs Institute for Evidence Based Nursing and Midwifery, Adelaide, No 14

Wilson P 2002 How to find the good and avoid the bad or ugly: a short guide to tools for rating quality of health information on the internet. British Medical J ournal 324(9 March):598-600

Wyatt J C 1997 Measuring quality and impact of the world wide web. British Medical J ournal 314(7098):1879 